\title{
Propagação in vitro de orquídea: iodeto de potássio e cloreto de cobalto em meio de cultura Knudson $\mathrm{C}$
}

\author{
Joyce Dória Rodrigues Soares ${ }^{1}$, Moacir Pasqual ${ }^{2}$, Filipe Almendagna Rodrigues ${ }^{3}$, Fabiola Villa ${ }^{4}$, Janice Guedes \\ de Carvalho ${ }^{5}$, Aparecida Gomes de Araujo ${ }^{1}$
}

\section{RESUMO}

Objetivou-se determinar modificações ao meio de cultura Knudson C, acrescendo-o de iodeto de potássio e cloreto de cobalto, para que proporcione maior crescimento em plântulas de Cattleya loddigesii. Plântulas de orquídea, oriundas de sementes germinadas in vitro, com, aproximadamente, $1,0 \mathrm{~cm}$ de comprimento, foram inoculadas em tubos de ensaio contendo $15 \mathrm{~mL}$ de meio de cultura Knudson C modificado, acrescido de iodeto de potássio $(0 ; 0,45 ; 0,9$ e 1,35 mg. $\left.\mathrm{L}^{-1}\right)$ e cloreto de cobalto $\left(0 ; 0,015 ; 0,030\right.$ e $\left.0,045 \mathrm{mg} . \mathrm{L}^{-1}\right)$, em todas as combinações possíveis. O meio de cultura teve seu $\mathrm{pH}$ ajustado para $5,8 \pm 0,1$ e foi solidificado com 5 g. $\mathrm{L}^{-1}$ de ágar antes da autoclavagem a $121^{\circ} \mathrm{C}$ e 1 atm por 20 minutos. Após a inoculação os tratamentos foram mantidos em sala de crescimento com irradiância de $35 \mu \mathrm{mol} . \mathrm{m}^{-2} . \mathrm{s}^{-1}$, temperatura de $25 \pm 1^{\circ} \mathrm{C}$ e fotoperíodo de 16 horas. Ao final de 120 dias, foram avaliados número de raízes, comprimento médio de raízes e da parte aérea e massa de matéria fresca de plântulas. O cloreto de cobalto, em sua maior concentração (0,045 $\left.\mathrm{mg} \mathrm{L}^{-1}\right)$, adicionado ao meio Knudson C modificado, sem a suplementação de iodeto de potássio, proporciona melhores resultados quanto ao crescimento in vitro das plântulas de Cattleya loddigesii.

Palavras-chave: Meio de cultura, micropropagação, Cattleya loddigesii Lindl.

\section{ABSTRACT}

\section{Orchids in vitro propagation: potassium iodide and cobalt chloride in Knudson C culture medium}

The aim of this study was to determine changes in the Knudson medium by supplementation with iodide potassium and cobalt chloride to improve the in vitro growth of Cattleya loddigesii Lindl. plantlets. In vitro seedlings of approximately $1 \mathrm{~cm}$ in length were inoculated on test tubes containing $15 \mathrm{~mL}$ of modified Knudson $\mathrm{C}$ medium, supplemented with iodide potassium $\left(0 ; 0.45 ; 0.90\right.$ and $\left.1.35 \mathrm{mg} . \mathrm{L}^{-1}\right)$ and cobalt chloride $\left(0 ; 0.015 ; 0.030\right.$ and $0.045 \mathrm{mg} . \mathrm{L}^{-}$ ${ }^{1}$ ) in all possible combinations. The $\mathrm{pH}$ of the culture medium was adjusted to $5.8 \pm 0.1$ and solidified with 5 g. $\mathrm{L}^{-1}$ of agar before sterilization at $121^{\circ} \mathrm{C}$ and $1 \mathrm{~atm}$ per 20 minutes. The cultures were maintained in growth room with irradiance around $35 \mu \mathrm{mol} . \mathrm{m}^{-2} . \mathrm{s}^{-1}$, temperature at $25 \pm 1^{\circ} \mathrm{C}$ and photoperiod of 16 hours. After 120 days, there were evaluated the number of roots, average length of roots and shoots and fresh weight of seedlings. The cobalt chloride at its highest concentration $\left(0,045 \mathrm{mg} \mathrm{L}^{-1}\right)$ added to the modified Knudson $\mathrm{C}$ without supplemental potassium iodide, gave the best results for the in vitro growth of Cattleya loddigesii seedlings.

Key words: Culture medium, Cattleya loddigesii Lindl., micropropagation.

\footnotetext{
Recebido para publicação em março de 2008 e aprovado em março de 2011

${ }^{1}$ Engenheiras-Agrônomas, Doutoras. Departamento de Agricultura, Universidade Federal de Lavras, Caixa Postal 3037, 37200-000, Lavras, Minas Gerais, Brasil. joycerodrigues01@yahoo.com.br; agaraujo2003@yahoo.com.br

${ }^{2}$ Engenheiro-Agrônomo, Doutor. Departamento de Agricultura, Universidade Federal de Lavras, Caixa Postal 3037, 37200-000, Lavras, Minas Gerais, Brasil. mpasqual@ufla.br ${ }^{3}$ Engenheiro-Agrônomo, Mestre. Departamento de Agricultura, Universidade Federal de Lavras, Caixa Postal 3037, 37200-000, Lavras, Minas Gerais, Brasil. filipealmendagna@ yahoo.com.br

${ }^{4}$ Engenheira-Agrônoma, Doutora. Universidade Federal do Oeste do Paraná, Rua Pernambuco, 1777, Centro, 85960-000, Marechal Candido Rondon, Paraná, Brasil. fvilla2003@libero.it

${ }^{5}$ Engenheira-Agrônoma, Doutora. Departamento de Ciências do Solo, Universidade Federal de Lavras, Caixa Postal 3037, 37200-000, Lavras, Minas Gerais, Brasil. janicegc@ ufla.br
} 


\section{INTRODUÇÃO}

A família Orchidaceae pode ser considerada um dos maiores e mais avançados grupos de vegetais superiores, tendo representantes em várias partes do planeta e nos mais diversos ambientes. Na floricultura sua presença se faz marcante, com flores de corte muito apreciadas pela beleza, durabilidade e longevidade (Hew, 2001).

Em se tratando de orquídeas, o estudo da nutrição mineral de plantas torna-se necessário, pois no processo de absorção, um determinado nutriente pode exercer influência sobre o outro, dadas as interações que podem ocorrer. Embora a possibilidade de ocorrer carência de um micronutriente seja menor do que de um macronutriente (Gomes \& Shepherd, 2000), é necessário aprofundar os conhecimentos sobre as reais necessidades da orquídea em micronutrientes, uma vez que, uma planta cultivada em meio pobre em minerais pode apresentar diminuição no seu crescimento (Malavolta, 2006).

O meio de cultura deve suprir tecidos e órgãos cultivados in vitro com nutrientes necessários ao crescimento. Dentre eles o cobalto intervém em vários segmentos do metabolismo dos carboidratos e proteínas, por sua participação em sistemas enzimáticos. O iodo pode ser um elemento essencial e, alternativamente, esse íon pode agir como agente redutor de várias reações químicas (Pasqual, 2001). O iodeto de potássio (KI) e o cloreto de cobalto hexa-hidratado $\left(\mathrm{CoCl}_{2} \cdot 6 \mathrm{H}_{2} 0\right)$ são componentes do meio MS (Murashige \& Skoog, 1962). Porém, esses micronutrientes não são adicionados ao meio Knudson C, usualmente empregado na micropropagação de orquídeas (Soares et al., 2009).

A escassez de informações sobre o uso de micronutrientes, em especial iodo e cobalto, no cultivo in vitro de orquídeas, justificou o presente trabalho, que objetivou determinar modificações ao meio de cultura Knudson C, acrescendo-o de $\mathrm{KI}$ e $\mathrm{CoCl}_{2} .6 \mathrm{H}_{2} \mathrm{O}$, de forma a proporcionar melhor desenvolvimento de plântulas de Cattleya loddigesii.

\section{MATERIAL E MÉTODOS}

Plântulas de Cattleya loddigesii, obtidas por germinação in vitro de sementes oriundas de auto-fecundação, foram submetidas à uniformização, em meio de cultura Knudson C (Knudson, 1946) modificado, em $\mathrm{ZnSO}_{4} .7 \mathrm{H}_{2} \mathrm{O}$ (de 0,331 para 6,62 mg.L $\mathrm{L}^{-1}$ ), $\mathrm{H}_{3} \mathrm{BO}_{3}$ (de 0,056 para $1,4 \mathrm{mg} . \mathrm{L}^{-1}$ ) e $\mathrm{MnSO}_{4} \mathrm{H}_{2} \mathrm{O}$, onde permaneceram por três meses para uniformização. Após este período, cada tubo de ensaio, com $15 \mathrm{~mL}$ de meio Knudson C (KC), foi inoculado com uma plântula de aproximadamente $1,0 \mathrm{~cm}$ de comprimento e acrescido de iodeto de potássio $(0 ; 0,45$; 0,9 e $\left.1,35 \mathrm{mg} . \mathrm{L}^{-1}\right)$ e cloreto de cobalto $(0 ; 0,015 ; 0,030$ e $\left.0,045 \mathrm{mg} . \mathrm{L}^{-1}\right)$, em todas as combinações possíveis. O meio de cultura teve seu $\mathrm{pH}$ ajustado para 5,8 $\pm 0,1$ e foi solidificado com $5 \mathrm{~g} . \mathrm{L}^{-1}$ de agar, antes da autoclavagem a $121^{\circ} \mathrm{C}$ e 1 atm, por 20 minutos. As plântulas foram mantidas em sala de crescimento com irradiância de $35 \mu \mathrm{mol} . \mathrm{m}^{-2} . \mathrm{s}^{-1}$, temperatura de $25 \pm 1{ }^{\circ} \mathrm{C}$ e fotoperíodo de 16 horas.

$\mathrm{O}$ delineamento experimental foi inteiramente casualizado, em esquema fatorial $4 \times 4$, com 16 tratamentos, contendo quatro repetições de cinco plântulas cada. Ao final de 120 dias, foram avaliados os números de raízes (NR), folhas (NF) e de brotos (NB), os comprimentos médio de raízes $(\mathrm{CR})$ e da parte aérea (CPA) e a massa de matéria fresca de plântulas (MFP). Os dados quantitativos foram comparados por meio de regressão polinomial, empregando-se o software Sisvar (Ferreira, 2000).

\section{RESULTADOS E DISCUSSÃO}

Utilizando-se o teste $\mathrm{F}$ a $5 \%$ de probabilidade, verificou-se que as variáveis números de folhas e de brotos não apresentaram diferença significativa entre os fatores estudados. Houve interação significativa para número de raízes, comprimento médio de raízes, comprimento da parte aérea e massa de matéria fresca de plântulas (Tabela 1).

Para número de raízes em plântulas, observou-se que a maior concentração de cloreto de cobalto $\left(0,045 \mathrm{mg} . \mathrm{L}^{-1}\right)$, associada a $0,45 \mathrm{mg} . \mathrm{L}^{-1}$ e na ausência de iodeto de potássio, ocorreram as maiores médias $(5,46$ e 5,56, respectivamente), de forma linear (Figura 1).

$\mathrm{O}$ meio Knudson $\mathrm{C}$ não possui em sua formulação fontes de iodo e cobalto. Pode-se inferir, com isso, que o acréscimo desses micronutrientes tenha aumentado o número de raízes em plântulas de orquídea, uma vez que o meio básico não proporcionou o mesmo enraizamento. Quando se aumenta a quantidade de raízes formadas in vitro, aumenta-se também a área de contato raiz/substrato e, por fim, espera-se que ocorra maior absorção dos nutrientes. Desta forma, o $\mathrm{CoCl}_{2} \cdot 6 \mathrm{H}_{2} \mathrm{O}$ contribuiu para o aumento do número de raízes. Kanashiro (2005) também observou em bromélias (Aechmea blanchetiana (Baker) L.B. Sm.) maior absorção de nutrientes em meio MS modificado em cobalto, ocasionando aumento no sistema radicular.

Para comprimento de raízes, houve significância entre as concentrações de cloreto de cobalto, na ausência e com $0,9 \mathrm{mg} . \mathrm{L}^{-1}$ de iodeto de potássio. Verificaram-se melhores respostas $(2,71 \mathrm{~cm})$ na ausência de KI e com a adição de $0,045 \mathrm{mg} . \mathrm{L}^{-1} \mathrm{de} \mathrm{CoCl}_{2} \cdot 6 \mathrm{H}_{2} \mathrm{O}$ ao meio Knudson $\mathrm{C}$ (Figura 2). A concentração de $0,9 \mathrm{mg} . \mathrm{L}^{-1}$ de iodeto de potássio associada a $0,023 \mathrm{mg} . \mathrm{L}^{-1}$ de cloreto de cobalto apresentou comprimento de raiz de 2,63 cm (Figura 2).

Num substrato com deficiência de nutrientes, como é o caso do meio Knudson C, aumentar o comprimento das raízes é uma maneira de a plântula buscar os nutrientes necessários ao seu desenvolvimento, mesmo que isto 
implique gasto de reservas. Na Figura 2, observa-se que a adição de $0,045 \mathrm{mg} . \mathrm{L}^{-1}$ de cloreto de cobalto no meio Knudson C influenciou o comprimento médio do sistema radicular desta maneira. Evidencia-se assim que, para promover maior comprimento médio do sistema radicular, a adição desta fonte de cobalto no meio Knudson é benéfica.

Reddy et al. (2001) verificaram $100 \%$ de enraizamento de plântulas de Decalepis hamiltonii Wight \& Arn. (Apocynaceae), em meio MS, e $80 \%$ de sobrevivência

Tabela 1. Resumo da análise de variância para os fatores número de folhas (NF), número de brotos (NB), número de raízes (NR), comprimento médio de raízes (CMR), comprimento da parte aérea (CPA), massa de matéria fresca de plântulas (MFP)

\begin{tabular}{|c|c|c|c|c|c|c|c|}
\hline \multirow{2}{*}{ Fonte de variação } & \multirow{2}{*}{ GL } & \multicolumn{3}{|c|}{ QM } & \multirow[b]{2}{*}{ CMR } & \multirow[b]{2}{*}{ CPA } & \multirow[b]{2}{*}{ MFP } \\
\hline & & NF & NB & NR & & & \\
\hline$\overline{\text { Iodo }}$ & 3 & $18,5210^{\mathrm{ns}}$ & $0,8386^{\mathrm{ns}}$ & 0,0699 ns & $0,3545^{*}$ & $1,3338 *$ & $0,0017^{\mathrm{ns}}$ \\
\hline Cobalto & 3 & 7,5393 ns & 0,2953 ns & $3,7883^{*}$ & $0,4675^{*}$ & 0,1297 ns & $0,0173 *$ \\
\hline I x Co & 9 & $12,4957^{\mathrm{ns}}$ & $0,5179^{\text {ns }}$ & $1,6048^{*}$ & $0,4013 *$ & $1,1245^{*}$ & $0,0089 *$ \\
\hline Resíduo & 48 & 15,0905 & 0,4491 & 0,5907 & 0,1398 & 0,2284 & 0,0020 \\
\hline$\overline{\mathrm{CV}(\%)}$ & & 35 & 35 & 17 & 17 & 19 & 29 \\
\hline
\end{tabular}

* significativo a $5 \%$ de probabilidade pelo teste de $\mathrm{F}$; ns não significativo.

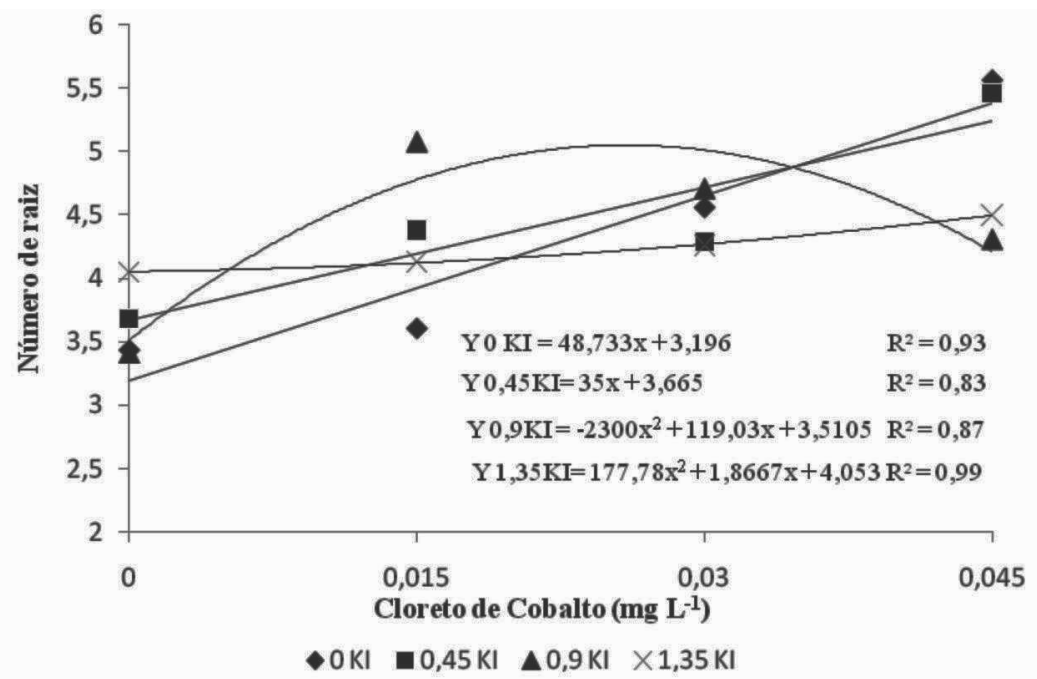

Figura 1. Número de raízes em plântulas de Cattleya loddigesii, cultivadas in vitro, em meio de cultura Knudson C, acrescido de diferentes concentrações de iodeto de potássio $(\mathrm{KI})$ e cloreto de cobalto $\left(\mathrm{CoCl}_{2}\right) \cdot 6 \mathrm{H}_{2} \mathrm{O}$.

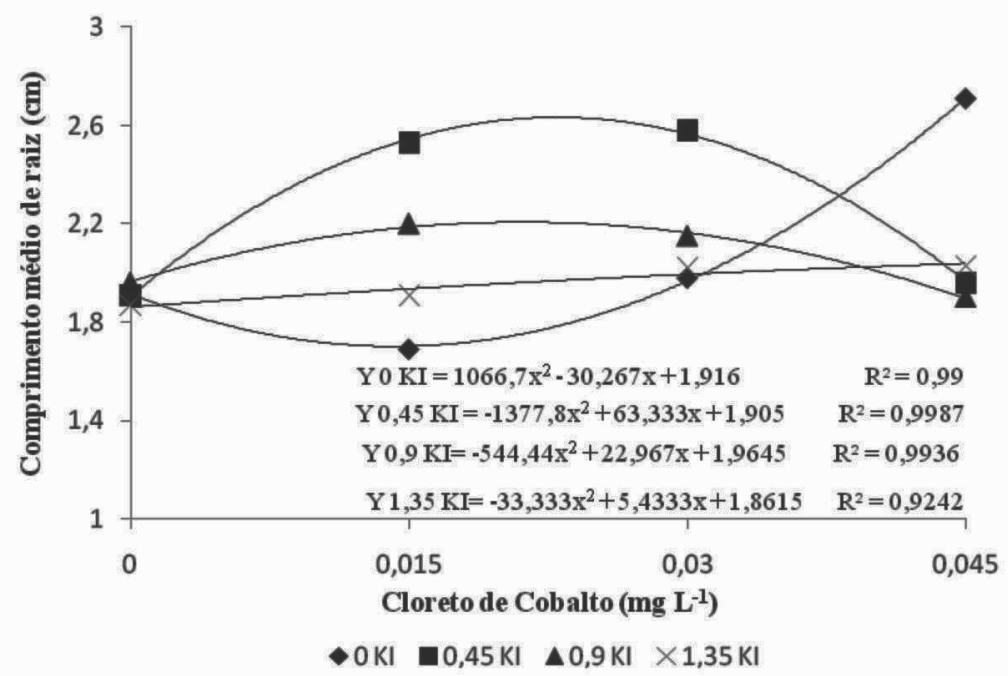

Figura 2. Comprimento de raízes em plântulas de Cattleya loddigesii, cultivadas in vitro, em meio de cultura Knudson C, acrescido de diferentes concentrações de cloreto de cobalto e iodeto de potássio. 
dessas plântulas no transplantio, com a adição de $5 \mu \mathrm{M}$ de cloreto de cobalto e 4,4 $\mu \mathrm{M}$ de AIB (ácido indolbutírico), respectivamente.

Na Figura 3, observa-se que com a máxima concentração de cloreto de cobalto acrescidas de $0,45 \mathrm{mg} \mathrm{L}^{-1}$ de iodeto de potássio e também em sua ausência, houve aumento de forma quadrática no comprimento das plântulas de orquídea, apresentando valores de 3,01 e 2,74 cm, respectivamente. Entretanto, quando se utilizou a concentração de $0,022 \mathrm{mg} . \mathrm{L}^{-1}$ de cloreto de cobalto combinada com 0,9 de KI, registraram-se os melhores resultados para esta variável $(3,32 \mathrm{~cm})$.

O crescimento de plantas, órgãos, tecidos e células in vitro depende do desenvolvimento de meios de cultura otimizados, para a perfeita interação de componentes essenciais, como fontes de carbono e nutrientes minerais.
Os fatores que limitam esse crescimento in vitro são similares àqueles in vivo (Amaral, 2003).

Para massa de matéria fresca de plântulas, observouse interação significativa dos fatores (Figura 4). Com incremento nas concentrações de cloreto de cobalto, verificou-se aumento de forma quadrática na massa de matéria fresca de plântulas, quando na ausência e com 0,9 mg.L $\mathrm{L}^{-1}$ de $\mathrm{KI}$; em 0,45 mg. $\mathrm{L}^{-1}$ de iodeto de potássio houve um aumento linear. Maior massa de matéria fresca de plântulas $(0,245 \mathrm{~g})$ foi obtida com $0,045 \mathrm{mg} . \mathrm{L}^{-1}$ de cloreto de cobalto na ausência de KI. Na concentração de $0,024 \mathrm{mg} \cdot \mathrm{L}^{-1}$ de cloreto de cobalto, combinada com 0,9 mg.L $\mathrm{L}^{-1}$ de KI, observou-se a mesma massa encontrada no tratamento com cloreto de cobalto $\left(0,045 \mathrm{mg} \cdot \mathrm{L}^{-1}\right)$. Houve diminuição da matéria fresca com incremento de $\mathrm{CoCl}_{2} \cdot 6 \mathrm{H}_{2} \mathrm{O}$. A ausência de resultados satisfatórios em todas as variáveis analisa-

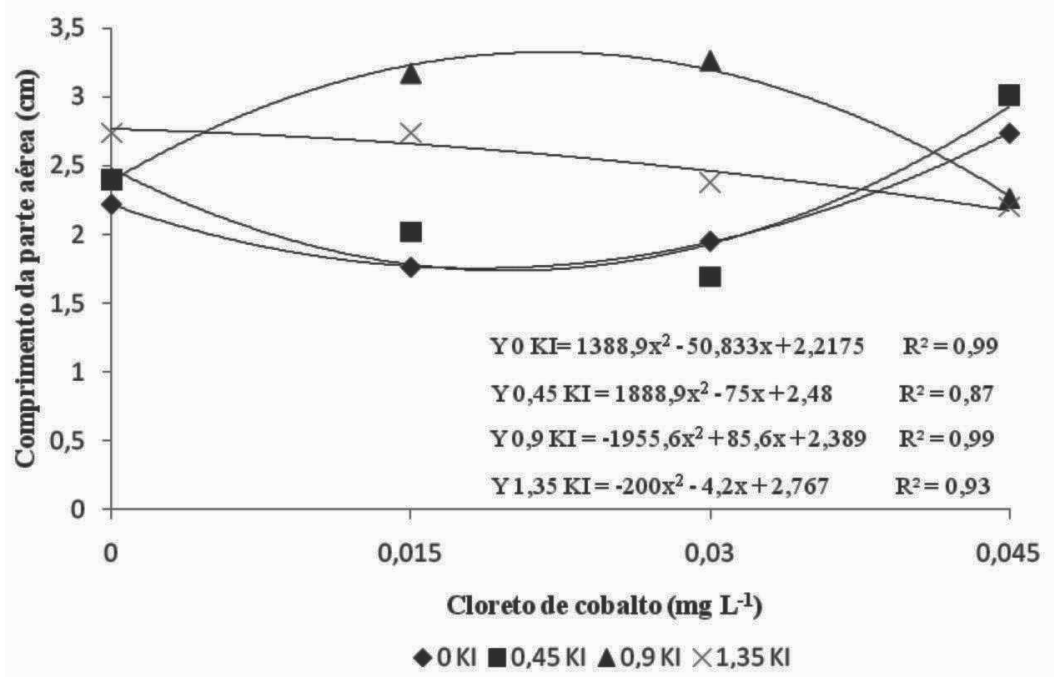

Figura 3. Comprimento da parte aérea em plântulas de Cattleya loddigesii, cultivadas in vitro, em meio de cultura Knudson C, acrescido de diferentes concentrações de cloreto de cobalto e iodeto de potássio.

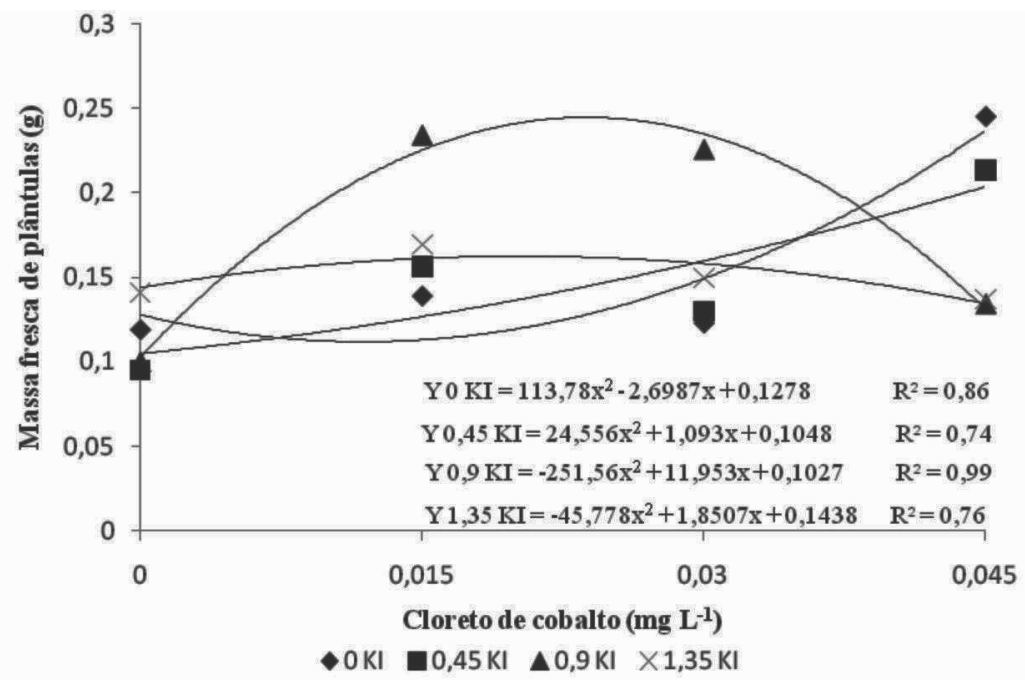

Figura 4. Massa de matéria fresca de plântulas de Cattleya loddigesii, cultivadas in vitro, em meio de cultura Knudson C, acrescido de diferentes concentrações de cloreto de cobalto e iodeto de potássio. 
das com o acréscimo de KI pode estar relacionada com o fato de que, apesar de o iodo ser um elemento essencial, esse íon pode agir como agente redutor (Pasqual, 2001), alterando o metabolismo da planta de forma prejudicial.

$\mathrm{O}$ fator nutricional depende do fluxo de densidade ou da quantidade de nutrientes utilizados por unidade de tempo e de área. A absorção de nutrientes minerais é afetada pela constituição do meio de cultura, pela composição do tecido da planta e pelo ambiente de cultura, fatores que poderiam prognosticar e, ou, predizer a adequada composição do meio nutritivo com base nas análises de tecidos de plantas crescidas in vitro (Willians, 1991).

\section{CONCLUSÃO}

O cloreto de cobalto, em sua maior concentração $(0,045$ $\mathrm{mg} \mathrm{L}^{-1}$ ), adicionado ao meio Knudson $\mathrm{C}$ modificado, sem a suplementação de iodeto de potássio, proporciona melhores resultados referentes ao crescimento in vitro das plântulas de Cattleya loddigesii.

\section{REFERÊNCIAS}

Amaral AFC (2003) Comportamento in vitro de explantes de matrizes de cenoura (Daucus carota L.) tratadas com variáveis níveis de potássio. Dissertação de Mestrado. Escola Superior de Agricultura Luiz de Queiroz, Piracicaba, 103p.

Ferreira DF (2000) Análises estatísticas por meio do SISVAR para windows versão 4.0. In: Reunião Anual da Região Brasileira da Sociedade Internacional de Biometria, 45, São Carlos. Anais, São Carlos. p.225-258.

Gomes MN \& Shepherd SK (2000) Estudo de nutrição mineral in vitro relacionado à adaptação de Sinningia allagophylla (Martius) Wiehler (Gesneriaceae) às condições de cerrado. Revista Brasileira Botânica, 23:153-159.

Hew CS (2001) Ancient Chinese orchid cultivation - A fresh look at an age-old practice. Scientia Horticulturae, 87:1-10.

Kanashiro S (2005) Nitrogênio, fósforo, potássio, cálcio e o crescimento de plântulas de Aechmea blanchetiana (Baker) L.B. Smith in vitro. Tese de Doutorado. Escola Superior de Agricultura Luiz de Queiroz, Piracicaba, 187p.

Knudson LA (1946) New nutrient solution for the germination of orchid seed. American Orchid Society Bulletim, 14:214-217.

Malavolta E (2006) Manual de nutrição mineral de plantas. 1. ed. Piracicaba, POTAFOS. 638p.

Murashige T \& Skoog F (1962) A revised medium for rapid growth and bioassays with tobacco tissue cultures. Physiologia Plantarum, 15:473-497.

Pasqual M (2001) Meios de cultura. Lavras, UFLA/FAEPE. 74p.

Reddy BO, Giridhar P \& Ravishankar GA (2001) In vitro rooting of Decalepis hamiltonii Wight \& Arn., an endangered shrub, by auxins and root-promoting agents. Current Science, 81:11.

Soares JDR, Araujo AG, Pasqual M, Rodrigues FA \& Assis FA (2009) Concentrações de sais do meio Knudson C e de ácido giberélico no crescimento in vitro de plântulas de orquídea. Ciência Rural, 2:772-777.

Willians RR (1991) Factors determining mineral uptake in vitro. Acta Horticulturae, 289:165-166. 